\title{
Symptom assessment and exercise impairment in surgical decision making in hypertrophic obstructive cardiomyopathy: Relationship to outcomes
}

\author{
Milind Y. Desai, MD, Nicholas G. Smedira, MD, Aditya Bhonsale, MD, Maran Thamilarasan, MD, \\ Bruce W. Lytle, MD, and Harry M. Lever, MD
}

\begin{abstract}
Objectives: We sought to assess the long-term outcomes in patients with hypertrophic cardiomyopathy and severe left ventricular outflow tract obstruction, in whom the decision regarding surgery (vs conservative management) was based on assessment of symptoms or exercise capacity.

Methods: This was an observational study of 1530 patients with hypertrophic cardiomyopathy (aged $50 \pm 13$ years, $63 \%$ were men) with severe left ventricular outflow tract obstruction (excluding those aged $<18$ years, with left ventricular ejection fraction $<50 \%$, and with left ventricular outflow tract gradient $<30 \mathrm{~mm} \mathrm{Hg}$ ). A composite end point of death (excluding noncardiac causes) and/or implantable defibrillator discharge was assessed.
\end{abstract}

Results: Coronary artery disease, family history of hypertrophic cardiomyopathy, and syncope were present in $15 \%, 17 \%$, and $18 \%$ of patients, respectively, whereas $73 \%$ patients were in New York Heart Association class II or greater. Mean left ventricular ejection fraction, basal septal thickness, and left ventricular outflow tract gradient (resting or provocable) were $62 \% \pm 5 \%, 2.2 \pm 1 \mathrm{~cm}$, and $101 \pm 39 \mathrm{~mm} \mathrm{Hg}$, respectively. A total of 858 patients (56\%) underwent exercise echocardiography, of whom $503(59 \%)$ had exercise capacity impairment. At $8.1 \pm 6$ years, 990 patients $(65 \%)$ underwent surgical relief of left ventricular outflow tract obstruction, and 540 patients $(35 \%)$ did not. There were 156 events (10\%) (134 deaths), with $0 \%$ 30-day mortality in the surgical group. On multivariable Cox proportional hazard analysis, increasing age (hazard ratio [HR], 1.20), coronary artery disease (HR, 1.68), worse New York Heart Association class (HR, 1.46), and atrial fibrillation (HR, 1.90) predicted higher events, whereas surgery (time-dependent covariate HR, 0.57) was associated with improved event-free survival (all $P<.01$ ).

Conclusions: In patients with hypertrophic cardiomyopathy and severe left ventricular outflow tract obstruction, in whom the decision regarding surgery was based on the presence of intractable symptoms and impaired exercise capacity, surgery was associated with significant improvement in long-term composite outcomes. (J Thorac Cardiovasc Surg 2015;150:928-35)

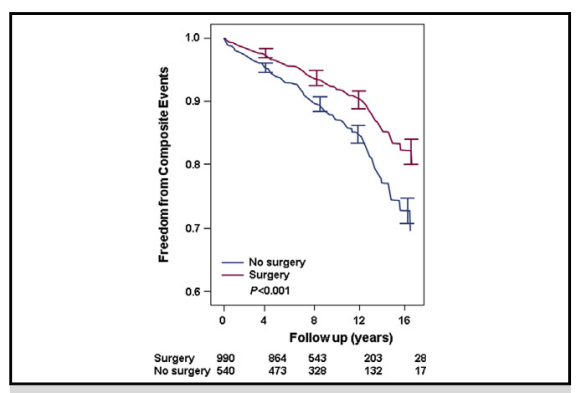

Outcomes of patients with HCM based on surgical myectomy versus conservative treatment.

\section{Central Message}

In HCM, surgical relief of severe LVOT obstruction resulted in improved freedom from long-term events versus conservative management.

\section{Perspective}

In patients with HCM and severe LVOT obstruction, in whom the decision regarding surgery (vs conservative management) was based on symptom assessment and exercise capacity, surgical relief of LVOT obstruction was associated with improved freedom from events (death or internal defibrillator discharge) when compared with conservative management.

See Editorial Commentary page 936.
丹 Supplemental material is available online.

From the Hypertrophic Cardiomyopathy Center, Heart and Vascular Institute, Cleveland Clinic, Cleveland, Ohio.

Received for publication April 21, 2015; revisions received July 1, 2015; accepted for publication July 16, 2015; available ahead of print Aug 28, 2015.

Address for reprints: Milind Y. Desai, MD, Heart and Vascular Institute, Cleveland Clinic, 9500 Euclid Ave, Desk J1-5, Cleveland, OH 44195 (E-mail: desaim2@ ccf.org).

$0022-5223 / \$ 36.00$

Copyright (c) 2015 by The American Association for Thoracic Surgery

http://dx.doi.org/10.1016/j.jtcvs.2015.07.063
Hypertrophic cardiomyopathy (HCM) is a commonly inherited cardiomyopathy with a varied phenotypic expression ranging from asymptomatic to congestive heart failure (CHF) to sudden death, which occurs in less than $1 \%$ per year. ${ }^{1-4}$ Left ventricular outflow tract (LVOT) obstruction and concomitant mitral regurgitation $(\mathrm{MR})^{5}$ 


$$
\begin{aligned}
& \text { Abbreviations and Acronyms } \\
& \begin{aligned}
\text { AF } & =\text { atrial fibrillation } \\
\text { CHF } & =\text { congestive heart failure } \\
\text { HCM } & =\text { hypertrophic cardiomyopathy } \\
\text { HR } & =\text { hazard ratio } \\
\text { ICD } & =\text { implantable cardioverter defibrillator } \\
\text { LV } & =\text { left ventricular } \\
\text { LVOT } & =\text { left ventricular outflow tract } \\
\text { METS } & =\text { metabolic equivalents } \\
\text { MR } & =\text { mitral regurgitation } \\
\text { NYHA } & =\text { New York Heart Association } \\
\text { VT } & =\text { ventricular tachycardia }
\end{aligned}
\end{aligned}
$$

result in reduced exercise capacity that, if uncorrected, can progress to CHF and death. LVOT obstruction is independently associated with adverse HCM-related outcomes. ${ }^{5,6}$ When evaluated carefully, LVOT obstruction is observed in approximately $70 \%$ of patients with $\mathrm{HCM}^{7}$ Surgical myectomy provides excellent long-term survival and freedom from recurrent symptoms in patients with obstructive HCM. ${ }^{8-12}$ However, most of these studies did not compare outcomes in patients with severe LVOT obstruction on the basis of whether surgical myectomy was performed or not.

Currently, it is a class I indication (level of evidence C) to offer invasive therapies (surgical myectomy \pm mitral valve surgery or alcohol septal ablation), at an experienced center, to patients with severe LVOT obstruction who are intractably symptomatic (New York Heart Association [NYHA] class III-IV), despite maximally tolerated medical therapy. ${ }^{3,4}$ However, patients' perception of their symptoms is often misleading, and in many instances, symptoms are equivocal. In such scenarios, exercise stress testing can unmask latent symptoms and help decision making. Although stress testing has been shown to potentially aid in risk stratification, ${ }^{13}$ there are not much data regarding its role in helping decide on surgery versus medical management. We sought to assess the long-term outcomes in patients with HCM and severe LVOT obstruction, in whom the decision regarding surgery (vs conservative management) was based on symptom assessment and objective evaluation of exercise capacity (in patients with NYHA class I-II).

\section{MATERIALS AND METHODS \\ Study Sample}

The study sample is part of an institutional review board-approved observational registry of patients with $\mathrm{HCM}$, with the initial visit between 1997 and 2011. We included 1530 consecutive patients with HCM (aged $\geq 18$ years) with significant LVOT obstruction who were evaluated at our tertiary care center, using the following exclusion criteria: (1) concomitant moderate or greater aortic/mitral stenosis on initial echocardiogram $(\mathrm{n}=151)$; (2) left ventricular (LV) ejection fraction less than $50 \%$
( $\mathrm{n}=30$ ); (3) maximal (including provokable) LVOT obstruction less than $30 \mathrm{~mm} \mathrm{Hg}(\mathrm{n}=368)$; (4) apical HCM variant $(\mathrm{n}=53)$; and (5) hypertensive heart disease in elderly patients $(\mathrm{n}=639) .^{14-16}$ Hypertensive heart disease in elderly patients was defined as a long-standing history of hypertension and characteristic sigmoid-shaped septal hypertrophy. ${ }^{14-16}$ These patients were excluded because they have a different pathophysiologic and genetic profile. The diagnosis of $\mathrm{HCM}$ was made by experienced cardiologists on the basis of typical features, with ventricular myocardial hypertrophy (LV wall thickness $\geq 15 \mathrm{~mm}$ ) occurring in the absence of any other disease responsible for hypertrophy. ${ }^{3,4}$ In addition, in patients with borderline LV wall thickness ( $\sim 15 \mathrm{~mm}$ ), the presence of resting/provocable LVOT obstruction (LVOT gradient $\geq 30 \mathrm{~mm} \mathrm{Hg}$ ) also aided in the diagnosis. ${ }^{3,4}$

Baseline clinical data were manually extracted from electronic medical records. Follow-up information was collected by manual extraction from electronic medical records and phone calls. The presence of atrial fibrillation (AF) was recorded on the basis of history, electrocardiograms, and Holter data. Nonsustained ventricular tachycardia (VT), wide complex tachycardia at 120 beats or more per minute (lasting $>3$ beats but $<30$ seconds), and sustained VT (lasting $>30$ seconds) were recorded according to history and Holter data. The presence of an implantable cardioverter defibrillator (ICD) and permanent pacemaker was ascertained

The primary indications to operate were (1) intractable symptoms (NYHA class III-IV, angina) despite maximal medical therapy; (2) exertional syncope (associated with elevated LVOT gradient); or (3) impaired exercise capacity on stress echocardiography, despite maximal medical therapy, defined as less than 7 metabolic equivalents (METS) or not achieving $85 \%$ of age- and gender-predicted METs. ${ }^{13}$ The decision regarding invasive therapies to relieve LVOT obstruction was made after a consensus between experienced cardiologists and cardiothoracic surgeons.

\section{Echocardiography}

All patients underwent comprehensive echocardiograms using commercially available instruments (Philips, Bothell, Wash; General Electric, Milwaukee, Wis; and Siemens, Malvern, Pa). Maximal end-diastolic LV wall thickness, LV dimensions, and left atrial area were measured according to guidelines. ${ }^{17}$ Resting LVOT peak velocity was measured by continuous-wave Doppler echocardiography, and pressure gradient was estimated by using the simplified Bernoulli equation. Care was taken to avoid contamination of LVOT waveform by MR. In patients with resting LVOT gradients less than $30 \mathrm{~mm} \mathrm{Hg}$, provocative maneuvers, including Valsalva and amyl nitrite, were used. In patients with low resting gradients or NYHA class I-II symptoms, we performed exercise echocardiography to assess for impairment of exercise capacity, blood pressure response, and maximal postexercise LVOT gradient, as described. ${ }^{13}$ In patients with resting peak LVOT gradient greater than $100 \mathrm{~mm} \mathrm{Hg}$, provocative maneuvers were not used. Maximal LVOT gradient was recorded and defined as the highest recorded gradient (resting or provoked, including exercise) in a patient. ${ }^{18}$ The degree of resting MR was assessed (none-severe) using multiple criteria. ${ }^{19}$ Grades of resting diastolic function were assigned on the basis of multiple criteria (E to A ratio, deceleration time, left atrial area, LV ejection fraction). ${ }^{20}$ Tissue Doppler data were incorporated where available.

\section{Outcomes Assessment}

The duration of follow-up ranged between initial office visit to event or last follow-up. Death notification was confirmed by observation of death certificate or verification with a family member. The cause of death was ascertained as sudden cardiac death, noncardiac death, or unknown after a review of records or discussion with family. Sudden death was defined as unexpected sudden collapse occurring less than 1 hour from symptom onset in otherwise stable patients. ${ }^{21}$ In addition, we recorded successful resuscitation from cardiac arrest or appropriate ICD shocks (with 
defibrillation threshold of $>200$ beats on electrocardiogram reviews). ${ }^{21}$ For the composite end point, we included sudden death (excluding documented noncardiac death due to cancer, liver failure, primary respiratory, or neurologic issues, but censoring at the time of event) and appropriate ICD discharge. Patients with an unknown cause of death were included as part of the composite outcome, as previously described. ${ }^{11}$ Admission for CHF was recorded. In addition, the presence and cause of stroke (transient or permanent) were recorded on the basis of clinical neurologic evaluation and appropriate neuroimaging. Arrhythmias, occurring during follow-up (AF, VT, and nonsustained VT), were recorded.

In patients who had undergone surgery to relieve LVOT obstruction, the date and type of surgical procedures performed were recorded: (1) myectomy, (2) myectomy + mitral valve repair/replacement, (3) myectomy + coronary artery bypass grafting, and (4) myectomy \pm coronary artery bypass grafting \pm valve surgery. The details of the surgical techniques by our group have been described. ${ }^{9,12,22}$ The basic technique of myectomy involved muscle resection below the membranous septum, removing muscle over both papillary muscles, and often extending to both trigones. In patients requiring mitral repair, the most common technique involved plication of A2 scallop of the anterior leaflet.

\section{Statistical Analysis}

Continuous variables are expressed as mean \pm standard deviation or median and compared using analysis of variance (normal distribution) or Mann-Whitney test (non-normal distribution). Categoric data are expressed as percentage and compared using the chi-square test. To assess outcomes, Cox proportional hazards analysis was used. Forward stepwise multivariable survival analysis was performed, adjusting for relevant variables associated with outcomes in patients with HCM ( $P$ value threshold $<.1$ was an entry cutoff). Myectomy and alcohol ablation were included as time-dependent covariates in Cox survival analysis. For each patient undergoing these procedures, the analysis time was modeled so that only the person-time after the procedure was included in the invasive group. The person-time before invasive therapy was included in the nonsurgical category. Hazard ratios with $95 \%$ confidence intervals were calculated. In addition, adjusted survival curves were generated from the Cox model to determine the cumulative proportion of events as a function over time. For the surgical patients, date of surgery was considered as "time-zero" on survival analysis. The discriminative ability of survival models was compared using the c-statistic. ${ }^{23}$ Statistical analysis was performed using SPSS version 11.5 (SPSS Inc, Chicago, Ill), Stata version 10.0 (StataCorp LP, College Station, Tex), and R 3.0.3 (R foundation for Statistical Computing, Vienna, Austria).

\section{RESULTS}

The clinical, rest, and stress echocardiographic data are shown in Tables 1 and 2 . A total of 1425 patients $(93 \%)$ had a maximal LVOT gradient $50 \mathrm{~mm} \mathrm{Hg}$ or greater (437 [81\%] in the nonsurgical group and $990[100 \%]$ in the surgical group).

During follow-up, 990 patients $(65 \%)$ underwent surgical relief of LVOT obstruction. Within the surgical group, the type of cardiac surgeries was as follows: isolated myectomy $(\mathrm{n}=663,67 \%)$, myectomy plus mitral surgery $(\mathrm{n}=226,23 \%)$, myectomy plus coronary artery bypass grafting $(\mathrm{n}=89,9 \%)$, and myectomy plus coronary artery bypass plus additional surgery $(\mathrm{n}=12,1.2 \%)$. In the subgroup with concomitant mitral surgery, only 36 patients $(16 \%)$ underwent valve replacement; the rest underwent
TABLE 1. Baseline characteristics of study sample

\begin{tabular}{|c|c|c|c|c|}
\hline Variable & $\begin{array}{c}\text { Total } \\
\mathbf{n}=\mathbf{1 5 3 0}\end{array}$ & $\begin{array}{c}\text { No surgery } \\
n=540\end{array}$ & $\begin{array}{l}\text { Surgery } \\
\mathbf{n}=990\end{array}$ & $\begin{array}{c}P \\
\text { value }\end{array}$ \\
\hline Age, y & $50 \pm 13$ & $50 \pm 14$ & $50 \pm 12$ & .9 \\
\hline Male gender & $965(63 \%)$ & $346(64 \%)$ & $619(63 \%)$ & .3 \\
\hline Body surface area $\left(\mathrm{m}^{2}\right)$ & $2.0 \pm 0.2$ & $2.0 \pm 0.2$ & $2.0 \pm 0.2$ & .3 \\
\hline Hypertension & $633(41 \%)$ & $217(40 \%)$ & $416(42 \%)$ & .3 \\
\hline Diabetes mellitus & $166(11 \%)$ & $60(11 \%)$ & $106(11 \%)$ & .4 \\
\hline $\begin{array}{l}\text { History of significant } \\
\text { CAD }\end{array}$ & $235(15 \%)$ & $57(11 \%)$ & $178(18 \%)$ & $<.001$ \\
\hline Family history of HCM & $254(17 \%)$ & $80(15 \%)$ & $174(18 \%)$ & .1 \\
\hline History of sudden death & $16(1 \%)$ & $19(1.5 \%)$ & $9(0.8 \%)$ & .2 \\
\hline Unexplained syncope & $271(18 \%)$ & $74(14 \%)$ & $197(20 \%)$ & .001 \\
\hline History of AF & $220(14 \%)$ & $60(11 \%)$ & $160(16 \%)$ & .004 \\
\hline History of stroke & $51(3 \%)$ & $17(3 \%)$ & $34(3 \%)$ & .5 \\
\hline Implantable defibrillator & $128(8 \%)$ & $50(9 \%)$ & $78(8 \%)$ & .5 \\
\hline Permanent pacemaker & $164(11 \%)$ & $52(10 \%)$ & $112(11 \%)$ & .2 \\
\hline Beta-blockers & $1127(74 \%)$ & $359(67 \%)$ & $768(78 \%)$ & $<.001$ \\
\hline Calcium channel blocker & $507(33 \%)$ & $166(31 \%)$ & $341(34 \%)$ & .08 \\
\hline Disopyramide & $81(5 \%)$ & $4(0.7 \%)$ & $64(7 \%)$ & $<.001$ \\
\hline Angina & $181(12 \%)$ & $50(9 \%)$ & $131(13 \%)$ & $<.001$ \\
\hline NYHA class & & & & $<.001$ \\
\hline I & $418(27 \%)$ & $264(49 \%)$ & $154(16 \%)$ & \\
\hline II & $803(52 \%)$ & $210(39 \%)$ & $593(60 \%)$ & \\
\hline III & $307(21 \%)$ & $66(12 \%)^{*}$ & $241(24 \%)$ & \\
\hline IV & $2(0.1 \%)$ & 0 & $2(0.2 \%)$ & \\
\hline
\end{tabular}

$C A D$, Coronary artery disease; $H C M$, hypertrophic cardiomyopathy; $A F$, atrial fibrillation; NYHA, New York Heart Association. *These patients underwent alcohol septal ablation.

transaortic repair. During follow-up, 29 patients $(3 \%)$ needed a repeat surgical procedure to relieve LVOT obstruction ( 24 or $83 \%$ requiring an additional mitral valve procedure). Also, 119 patients ( $8 \%$ ) had invasive therapies (surgical Maze or pulmonary vein isolation) for relief of AF. The median time from initial evaluation to surgery was 45 days (1-5140 days). The indications for surgery were as follows: NYHA class III/IV or intractable angina $(\mathrm{n}=374)$, exertional syncope with severe $(>50 \mathrm{~mm} \mathrm{Hg})$ LVOT obstruction $(\mathrm{n}=113)$, and impaired exercise capacity $(\mathrm{n}=503)$. Patients in the surgical group, deemed in NYHA class I, had additional reasons (ie, exertional syncope with severe LVOT obstruction or impaired exercise capacity) to recommend surgery.

In the nonsurgical group, $49 \%$ of patients were in NYHA class I at initial presentation and remained asymptomatic during follow-up. The $12 \%$ of patients $(n=66)$ in the nonsurgical group who reported NYHA class III symptoms underwent alcohol septal ablation during follow-up. Within the nonsurgical group, the remaining patients (those with NYHA class II $[n=210]$ or angina $[n=50]$ at baseline) were not offered surgery because the symptoms were adequately controlled with medical therapy. Likewise, in the nonsurgical patients with a history of syncope, 31 patients with LVOT obstruction greater than $50 \mathrm{~mm} \mathrm{Hg}$ underwent alcohol ablation, whereas the remainder had an 
TABLE 2. Echocardiographic parameters of study sample

\begin{tabular}{|c|c|c|c|c|}
\hline Variable & Total $(\mathbf{n}=1530)$ & $\begin{array}{c}\text { No surgery } \\
\mathrm{n}=\mathbf{5 4 0}\end{array}$ & $\begin{array}{l}\text { Surgery } \\
\mathbf{n}=990\end{array}$ & $P$ value \\
\hline LV ejection fraction $(\%)$ & $62 \pm 5$ & $62 \pm 5$ & $62 \pm 5$ & .3 \\
\hline Indexed LV end-diastolic dimension $\left(\mathrm{cm} / \mathrm{m}^{2}\right)$ & $2.1 \pm 0.3$ & $2.1 \pm 0.4$ & $2.0 \pm 0.3$ & .1 \\
\hline Indexed LV end-systolic dimension $\left(\mathrm{cm} / \mathrm{m}^{2}\right)$ & $1.2 \pm 0.3$ & $1.2 \pm 0.3$ & $1.2 \pm 0.3$ & .9 \\
\hline Maximal LV thickness $(\mathrm{cm})$ & $2.0 \pm 0.3$ & $2.0 \pm 0.2$ & $2.0 \pm 0.2$ & .3 \\
\hline Indexed left atrial dimensions $\left(\mathrm{cm} / \mathrm{m}^{2}\right)$ & $2.2 \pm 0.4$ & $2.2 \pm 0.4$ & $2.3 \pm 0.4$ & .1 \\
\hline Resting MR & & & & $<.001$ \\
\hline None & $64(4 \%)$ & $30(6 \%)$ & $34(3 \%)$ & \\
\hline $1+$ & $921(60 \%)$ & $368(68 \%)$ & $553(56 \%)$ & \\
\hline II + & $387(25 \%)$ & $108(20 \%)$ & $279(28 \%)$ & \\
\hline III + & $134(9 \%)$ & $26(5 \%)$ & $108(11 \%)$ & \\
\hline IV+ & $24(1.6 \%)$ & $8(1.5 \%)$ & $16(1.6 \%)$ & \\
\hline Diastolic function & & & & .005 \\
\hline Impaired relaxation & $1392(91 \%)$ & $509(94 \%)$ & $883(89 \%)$ & \\
\hline Pseudonormal & $132(8 \%)$ & $31(6 \%)$ & $101(10 \%)$ & \\
\hline Restrictive filling & $6(1 \%)$ & 0 & $6(0.6 \%)$ & \\
\hline Resting LVOT gradient (mm Hg) & $51 \pm 41$ & $39 \pm 36$ & $58 \pm 42$ & $<.001$ \\
\hline Maximal LVOT gradient mm $\mathrm{Hg}$ & $101 \pm 39$ & $100 \pm 50$ & $102 \pm 41$ & .1 \\
\hline Systolic anterior motion of mitral valve & $1329(87 \%)$ & $438(81 \%)$ & $891(90 \%)$ & $<.001$ \\
\hline Exercise echocardiography & $858(56 \%)$ & $355(66 \%)$ & $503(51 \%)$ & $<.001$ \\
\hline Maximum METs $<7 *$ & $503(59 \%)$ & 0 & $503(100 \%)$ & $<.001$ \\
\hline$>100 \%$ age- and gender-predicted METs & $503(59 \%)$ & 0 & $503(100 \%)$ & $<.001$ \\
\hline Maximum METs achieved & $6.6 \pm 1.3$ & $8.1 \pm 1.1$ & $5.2 \pm 1$ & $<.001$ \\
\hline Abnormal blood pressure response to exercise & $9(0.5 \%)$ & $3(0.5 \%)$ & $6(0.6 \%)$ & .5 \\
\hline
\end{tabular}

$L V$, Left ventricle; $M R$, mitral regurgitation; $L V O T$, left ventricular outflow tract; METs, metabolic equivalents. *The percentages represent only those patients who underwent stress echocardiography.

LVOT gradient of less than $50 \mathrm{~mm} \mathrm{Hg}$, and thus invasive therapies were not offered. The 3 patients in the nonsurgical group with abnormal blood pressure response underwent alcohol ablation.

A total of 282 patients (18\%) (74 [14\%] in the nonsurgical group, of whom 64 were in NYHA class I/II at baseline, and 208 [24\%] in the surgical group, $P<.001$ ) had evidence of AF during long-term follow-up and were treated with medications (263 with amiodarone, 7 with dofetilide, and the rest using rate control). Nonsustained and sustained VT were noted in 154 patients $(10 \%)$ and 8 patients $(0.9 \%)$, respectively, with no difference between groups. Also, during follow-up, there were an additional 172 patients $(11 \%)$ with pacemakers, resulting in a total of 266 patients $(17 \%)(74[14 \%]$ in the nonsurgical group and $192[19 \%]$ in the surgical group, $P=.003)$. Likewise, there were an additional 276 patients $(18 \%)$ with ICDs, resulting in a total of 404 patients $(26 \%)$ (113 or $21 \%$ in the nonsurgical group and 291 patients or $29 \%$ in the surgical group, $P=.01$ ).

During a mean follow-up of $8.1 \pm 6$ years, 22 patients $(1.4 \%)$ progressed to NYHA class III-IV (7 [1\%] in the surgery group and $15[3 \%]$ in the nonsurgery group, $P=.04)$, whereas 44 patients $(2 \%)$ had a stroke, with no difference between subgroups $(1.8 \%$ vs $2.1 \%, P=.4)$. The 15 patients in the nonsurgical group who progressed to NYHA class III-IV did not have LVOT obstruction greater than $50 \mathrm{~mm} \mathrm{Hg}$ to justify surgery. A total of 156 patients $(10 \%)$ met the composite end point. The composite outcome included the following: 134 deaths (9\%) (89 documented sudden cardiac deaths and 45 unknown) and 31 appropriate ICD discharges $(2 \%)$. In patients in whom multiple end points developed, time to first event was used as an event time cutoff. An additional 17 patients $(1 \%)$ died of documented noncardiac causes during follow-up and were not included in the survival analysis (but were censored at time of death). The breakdown of composite events in patients who underwent surgery versus those who did not was as follows: 82 of $990(8 \%)$ versus 74 of $540(14 \%)(P<.001)$. There were no deaths in 30 days (or before hospital discharge) after myectomy. Twelve patients $(18 \%)$ in the group who underwent isolated alcohol septal ablation $(n=66)$ had an event during long-term follow up.

The data on forward stepwise multivariable Cox proportional hazard analysis are shown in Table 3. Alcohol septal ablation did not independently affect outcomes (hazard ratio, $1.35[0.74-2.40], P=.3$ ). For association with composite events, the c-statistic for baseline predictors (age, CAD, and NYHA class) was 0.62 (0.57-0.68). Addition of AF during follow-up increased the c-statistic to $0.68(0.62-0.76)(P=.02)$. Further addition of surgical 
TABLE 3. Forward stepwise multivariable Cox proportional hazard analysis for composite end points

\begin{tabular}{|c|c|c|}
\hline Variable & HR & $P$ value \\
\hline \multicolumn{3}{|c|}{$\begin{array}{l}\text { Model with relevant predictors associated with outcome in patients with } \\
\text { HCM }\end{array}$} \\
\hline Age (for 10-y increase) & $1.20(1.02-1.40)$ & .02 \\
\hline Coronary artery disease & $1.68(1.13-2.51)$ & .01 \\
\hline NYHA class & $1.46(1.15-1.86)$ & .002 \\
\hline $\begin{array}{l}\text { Surgery to relieve LVOT obstruction } \\
\text { (time-dependent covariate) }\end{array}$ & $0.57(0.40-0.79)$ & .001 \\
\hline $\mathrm{AF}$ & $1.90(1.32-2.72)$ & $<.001$ \\
\hline \multicolumn{3}{|l|}{ Chi-square for the model $51, P<.001$} \\
\hline \multicolumn{3}{|c|}{$\begin{array}{l}\text { The following variables were considered for the stepwise multivariable model: age, } \\
\text { gender, NYHA class at initial visit, syncope, family history of HCM, history of } \\
\text { sudden death, hypertension, cardiac medications at or after initial visit, maximal } \\
\text { LV wall thickness, indexed left atrial area, maximal LVOT gradient, VT, AF, alcohol } \\
\text { septal ablation (as a time-dependent covariate), surgery to relieve LVOT obstruction } \\
\text { (as a time-dependent covariate), and time to surgery. HR, Hazard ratio; } \\
\text { HCM, hypertrophic cardiomyopathy; NYHA, New York Heart Association; } \\
\text { LVOT, left ventricular outflow tract; } A F \text {, atrial fibrillation. }\end{array}$} \\
\hline
\end{tabular}

relief of LVOT obstruction increased the c-statistic to 0.75 (0.70-0.79) $(P=.01)$.

The proportion of events increased significantly with worsening baseline NYHA class (30/418 [7\%] in class I, $84 / 805[10 \%]$ in class II, and 42/307 [14\%] in class III/IV, $P<.001)$. The survival curves, separated on the basis of worsening baseline NYHA class, adjusted for variables listed in Table 3, are shown in Figure 1. In patients who presented with NYHA class I and II at baseline, the proportion of long-term events was $10 \%$ and $17 \%$ in the nonsurgical group compared with $4.5 \%$ and $8 \%$ in the surgical group, respectively (both $P<.001$ ).

The survival curves, separated on the basis of having undergone surgical relief of LVOT obstruction, adjusted for variables listed in Table 3, are shown in Figure 2. Likewise, the proportion of events was significantly lower in patients who remained free of $\mathrm{AF}$ versus those who had AF during follow-up (107/1248 [9\%] vs 49/282 [17\%], $P=.001$ ). The adjusted survival curves of patients based on the presence of AF during follow are shown in Figure 3.

Additional survival analyses (ie, excluding patients with alcohol septal ablation or significant coronary artery disease and only patients with maximal LVOT gradient $\geq 50 \mathrm{~mm}$ $\mathrm{Hg}$ ) are shown in the Appendix.

\section{DISCUSSION}

In the current study of patients with HCM with significant dynamic LVOT obstruction, in whom the decision regarding surgery (vs conservative management) was based on symptom assessment or objective evaluation of exercise capacity, we demonstrate that patients who underwent surgical relief of LVOT obstruction had significantly improved long-term outcomes versus those managed conservatively. Despite a higher proportion of

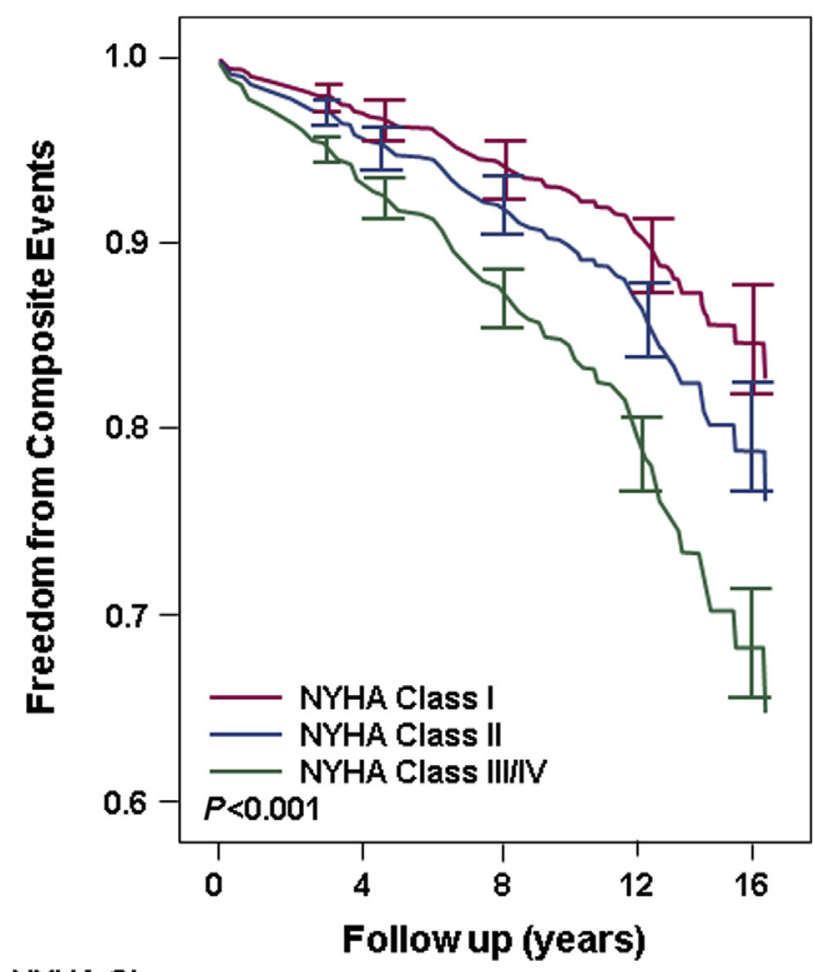

NYHA Class

$\begin{array}{rccccc}\text { I } & 418 & 378 & 244 & 88 & 14 \\ \text { II } & 805 & 706 & 479 & 179 & 27 \\ \text { IIIIV } & 307 & 253 & 148 & 68 & 4\end{array}$

FIGURE 1. Adjusted survival curves demonstrating long-term outcomes, separated on the basis of NYHA class. NYHA, New York Heart Association.

risk factors (symptoms, $\mathrm{AF}$, and $\mathrm{CAD}$ ) and poorer exercise capacity in the surgical versus nonsurgical group, the outcomes were significantly better after surgery.

Multiple previous reports have suggested that an elevated LVOT gradient is associated with worse long-term outcomes. ${ }^{5,6}$ In patients with LVOT obstruction, the survival was better in patients with NYHA class I than in those with class II and III/IV (91\% vs $83 \%$ and $82.6 \%$, respectively, $P<.05){ }^{6}$ Another study demonstrated that LVOT obstruction increased the risk of HCM-related death. ${ }^{4}$ If evaluated diligently using provocative maneuvers, an elevated LVOT gradient is seen in approximately $70 \%$ of patients. $^{7}$ Also, patients commonly misjudge their symptoms, and stress testing can help further elucidate their functional capacity. In a recent study, $82 \%$ of patients with $\mathrm{HCM}$, despite claiming to be asymptomatic, did not achieve $100 \%$ of their age- and gender-predicted METs, ${ }^{13}$ with those achieving less than $100 \%$ faring significantly worse than those who did.

Because surgical myectomy provides excellent long-term freedom from symptoms and outcomes, ${ }^{8-12}$ current guidelines give it a class I indication in patients with obstructive HCM, if performed at an experienced 


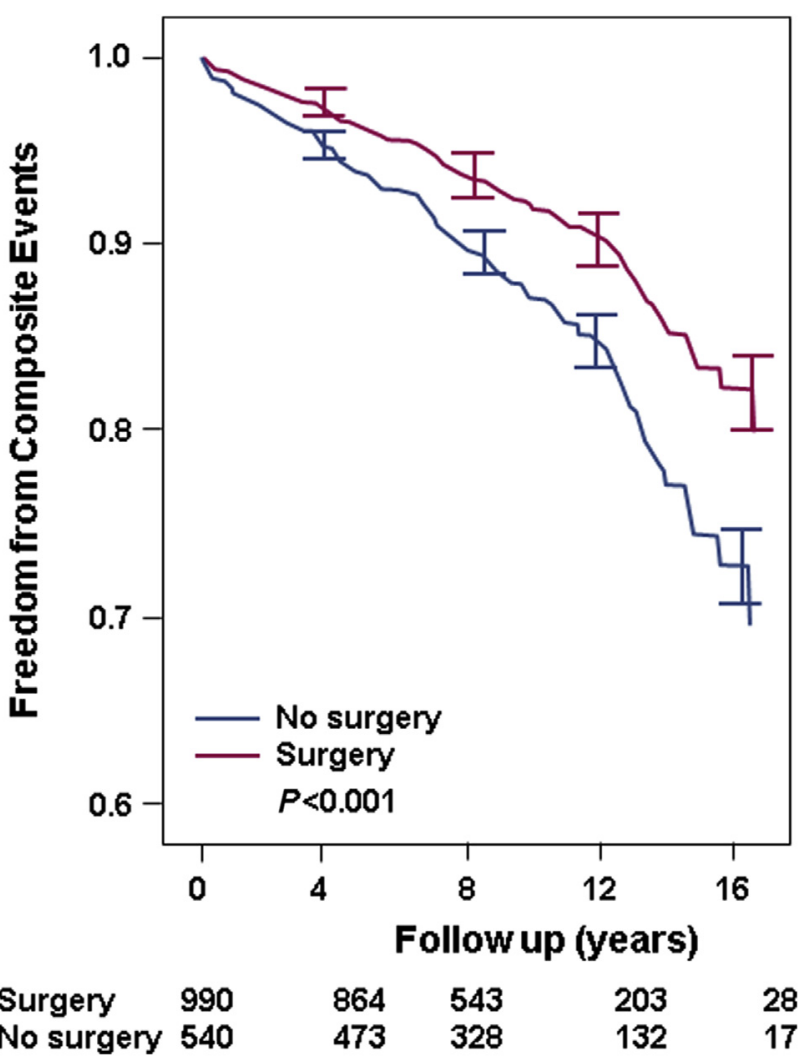

FIGURE 2. Adjusted survival curves demonstrating long-term outcomes, separated on the basis of surgical relief of LVOT obstruction.

center. ${ }^{3,4}$ However, it is recommended only in those patients who present with advanced intractable symptoms (NYHA class III-IV, angina, and syncope). ${ }^{3}$ This recommendation is based on a level of evidence $\mathrm{C}$, implying a consensus opinion based on small studies. Most of the previous studies that reported outcomes in patients undergoing myectomy did not use a strategy in which the decision regarding surgery (vs conservative management) was based on symptom assessment or objective evaluation of exercise capacity. Two prior reports have attempted to compare outcomes in patients with obstructive HCM, based on whether they underwent surgical relief of LVOT obstruction or not. In one study, the authors compared the outcomes in $3 \mathrm{HCM}$ subgroups: nonobstructive $(\mathrm{n}=820)$, obstructive without subsequent myectomy $(\mathrm{n}=228)$, and obstructive with subsequent myectomy $(\mathrm{n}=289){ }^{8}$ They demonstrated that the patients who underwent myectomy had the best outcomes, whereas the patients with obstructive HCM without myectomy had the worst outcomes. However, in addition to having a smaller sample size of patients with obstructive HCM, $78 \%$ of patients were evaluated at centers with large cohorts but not with specialized surgical experience in this disease. Another study by Ball and colleagues, ${ }^{11}$ evaluating 649 patients with HCM with resting LVOT obstruction treated invasively versus conservatively, demonstrated that

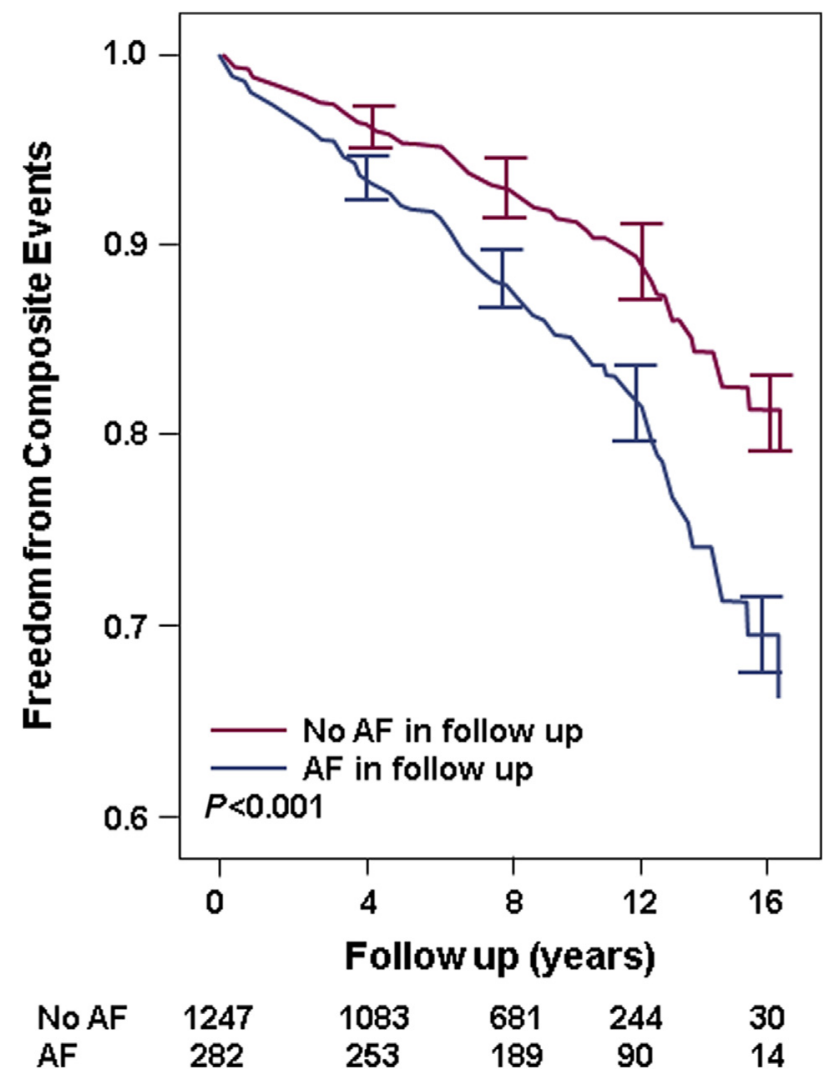

FIGURE 3. Adjusted survival curves demonstrating long-term outcomes, separated on the basis of AF during follow-up. $A F$, Atrial fibrillation.

overall survival was greater in the invasive group. ${ }^{11}$ However, invasive therapy did not independently predict HCMrelated events. Unlike the previous report, ${ }^{8}$ a major strength of the study by Ball and colleagues ${ }^{11}$ was that it was conducted in a single center with substantial experience in all forms of invasive therapies. However, the entry criteria were primarily based on resting LVOT gradient. Furthermore, pacing (used as a first-line invasive therapy) could have adversely affected outcomes. Also, the study was likely underpowered to detect differences in HCM-based outcomes. The current study was conducted in a single center with substantial experience in all forms of invasive therapies with a larger sample size. In addition, stress echocardiography was used as a strategy to further elucidate symptoms and help decide on the timing of surgery in selected patients. We also demonstrate that in the nonsurgical group, despite a low rate of progression of patients with NYHA class I/II at baseline to NYHA class III/IV during follow-up, the composite event rate was twice as high as in similar patients in the surgical group. The current study also underscores the importance of experience in the invasive management of patients with HCM with severe LVOT obstruction. In a recent analysis of the Nationwide Inpatient Sample, the authors demonstrated a 30-day mortality of $5.9 \%$ in patients undergoing surgical myectomy 
for relief of LVOT obstruction. ${ }^{24}$ This database represents the largest publically available all-payer US inpatient database, and the study population represents approximately $20 \%$ sample of US community hospitals. The results of that study underscore the importance of having myectomy performed at experienced centers. ${ }^{7,9,11}$ In fact, a sizable proportion of patients with symptomatic HCM with severe LVOT obstruction, especially those with basal septal thickness less than $1.8 \mathrm{~cm}$, have mitral valve abnormalities contributing to LVOT obstruction. As shown recently, more than $50 \%$ of such patients would require a concomitant surgical procedure (most likely anterior mitral leaflet repair or papillary muscle surgery) to relieve LVOT obstruction, further underscoring the importance of an experienced center. ${ }^{12,22,25}$

There are many potential reasons for improvement in HCM-related outcomes after surgery. An obvious reason is LVOT obstruction and symptomatic relief, with resultant increased exercise capacity and improved longevity. Another potential reason is that an extensive surgical myectomy removes a substantial amount of hypertrophied muscle. Previous reports have demonstrated that there is a significant association between LV hypertrophy and associated myocardial fibrosis. ${ }^{18}$ Thus, septal debulking could indirectly reduce the burden of myocardial fibrosis, which could be associated with a reduced incidence of $\mathrm{VT} .^{26}$

\section{Study Limitations}

This was an observational study from a single tertiary center, which could have selection bias. The results of all testing were available to all clinicians at the time of decision-making, introducing further bias. However, to truly understand the impact of surgical relief versus watchful waiting on outcomes, a large-scale prospective study would have to be conducted in patients with HCM with severe LVOT obstruction. However, a prospective, randomized trial in HCM has many inherent challenges. ${ }^{27}$ By study design, patients with LV dysfunction were not included in the study, and thus the results cannot be extrapolated to those groups. In addition, given the overall expertise involved with both the conservative and the invasive management of HCM, our results might not be generalizable to other lesser-experienced centers. ${ }^{24} \mathrm{We}$ do not have stress echocardiographic data during follow-up.

\section{CONCLUSIONS}

In a large group of patients with HCM and significant LVOT obstruction, in whom the decision regarding surgery (vs conservative management) was based on a combination of symptom assessment and objective evaluation of exercise capacity (especially in patients who perceive themselves as not very symptomatic), surgical relief of LVOT obstruction was associated with significantly improved long-term freedom from composite end points of HCM-related death and appropriate ICD discharge when compared with conservative management.

\section{Conflict of Interest Statement}

Authors have nothing to disclose with regard to commercial support.

\section{References}

1. Maron BJ. Hypertrophic cardiomyopathy: a systematic review. JAMA. 2002;287: 1308-20.

2. Elliott P, McKenna WJ. Hypertrophic cardiomyopathy. Lancet. 2004;363: 1881-91.

3. Gersh BJ, Maron BJ, Bonow RO, Dearani JA, Fifer MA, Link MS, et al. 2011 ACCF/AHA guideline for the diagnosis and treatment of hypertrophic cardiomyopathy. Circulation. 2011;124:e783-831.

4. Elliott PM, Anastasakis A, Borger MA, Borggrefe M, Cecchi F, Charron P, et al. 2014 ESC Guidelines on diagnosis and management of hypertrophic cardiomyopathy. Eur Heart J. 2014;35:2733-79.

5. Maron MS, Olivotto I, Betocchi S, Casey SA, Lesser JR, Losi MA, et al. Effect of left ventricular outflow tract obstruction on clinical outcome in hypertrophic cardiomyopathy. N Engl J Med. 2003;348:295-303.

6. Elliott PM, Gimeno JR, Tome MT, Shah J, Ward D, Thaman R, et al. Left ventricular outflow tract obstruction and sudden death risk in patients with hypertrophic cardiomyopathy. Eur Heart J. 2006;27:1933-41.

7. Maron MS, Olivotto I, Zenovich AG, Link MS, Pandian NG, Kuvin JT, et al. Hypertrophic cardiomyopathy is predominantly a disease of left ventricular outflow tract obstruction. Circulation. 2006;114:2232-9.

8. Ommen SR, Maron BJ, Olivotto I, Maron MS, Cecchi F, Betocchi S, et al. Longterm effects of surgical septal myectomy on survival in patients with obstructive hypertrophic cardiomyopathy. J Am Coll Cardiol. 2005;46:470-6.

9. Smedira NG, Lytle BW, Lever HM, Rajeswaran J, Krishnaswamy G, Kaple RK, et al. Current effectiveness and risks of isolated septal myectomy for hypertrophic obstructive cardiomyopathy. Ann Thorac Surg. 2008;85:127-33.

10. Woo A, Williams WG, Choi R, Wigle ED, Rozenblyum E, Fedwick K, et al. Clinical and echocardiographic determinants of long-term survival after surgical myectomy in obstructive hypertrophic cardiomyopathy. Circulation. 2005;111: 2033-41.

11. Ball W, Ivanov J, Rakowski H, Wigle ED, Linghorne M, Ralph-Edwards A, et al. Long-term survival in patients with resting obstructive hypertrophic cardiomyopathy comparison of conservative versus invasive treatment. J Am Coll Cardiol. 2011;58:2313-21.

12. Desai MY, Bhonsale A, Smedira N, Naji P, Thamilarasan M, Lytle B, et al. Predictors of long term outcomes in symptomatic hypertrophic obstructive cardiomyopathy patients undergoing surgical relief of left ventricular outflow tract obstruction. Circulation. 2013;128:209-16.

13. Desai MY, Bhonsale A, Patel P, Naji P, Smedira NG, Thamilarasan M, et al. Exercise echocardiography in asymptomatic HCM: exercise capacity, and not LV outflow tract gradient predicts long-term outcomes. JACC Cardiovasc Imaging. 2014;7:26-36.

14. Topol EJ, Traill TA, Fortuin NJ. Hypertensive hypertrophic cardiomyopathy of the elderly. N Engl J Med. 1985;312:277-83.

15. Lever HM, Karam RF, Currie PJ, Healy BP. Hypertrophic cardiomyopathy in the elderly. Distinctions from the young based on cardiac shape. Circulation. 1989; 79:580-9.

16. Binder J, Ommen SR, Gersh BJ, Van Driest SL, Tajik AJ, Nishimura RA, et al. Echocardiography-guided genetic testing in hypertrophic cardiomyopathy: septal morphological features predict the presence of myofilament mutations. Mayo Clin Proc. 2006;81:459-67.

17. Lang RM, Bierig M, Devereux RB, Flachskampf FA, Foster E, Pellikka PA, et al. Recommendations for chamber quantification. J Am Soc Echocardiogr. 2005;18: 1440-63.

18. Kwon DH, Smedira NG, Rodriguez ER, Tan C, Setser R, Thamilarasan M, et al. Cardiac magnetic resonance detection of myocardial scarring in hypertrophic cardiomyopathy: correlation with histopathology and prevalence of ventricular tachycardia. J Am Coll Cardiol. 2009;54:242-9.

19. Zoghbi WA, Enriquez-Sarano M, Foster E, Grayburn PA, Kraft CD, Levine RA, et al. Recommendations for evaluation of the severity of native valvular regurgitation with two-dimensional and Doppler echocardiography. J Am Soc Echocardiogr. 2003;16:777-802. 
20. Nagueh SF, Appleton CP, Gillebert TC, Marino PN, Oh JK, Smiseth OA, et al. Recommendations for the evaluation of left ventricular diastolic function by echocardiography. Eur J Echocardiogr. 2009;10:165-93.

21. Maron BJ, Olivotto I, Spirito P, Casey SA, Bellone P, Gohman TE, et al. Epidemiology of hypertrophic cardiomyopathy-related death: revisited in a large nonreferral-based patient population. Circulation. 2000;102:858-64.

22. Kwon DH, Smedira NG, Thamilarasan M, Lytle BW, Lever H, Desai MY. Characteristics and surgical outcomes of symptomatic patients with hypertrophic cardiomyopathy with abnormal papillary muscle morphology undergoing papillary muscle reorientation. J Thorac Cardiovasc Surg. 2009;54:242-9.

23. Uno H, Cai T, Pencina MJ, D’Agostino RB, Wei LJ. On the C-statistics for evaluating overall adequacy of risk prediction procedures with censored survival data. Stat Med. 2011;30:1105-17.

24. Panaich SS, Badheka AO, Chothani A, Mehta K, Patel NJ, Deshmukh A, et al. Results of ventricular septal myectomy and hypertrophic cardiomyopathy (from Nationwide Inpatient Sample [1998-2010]). Am J Cardiol. 2014;114:1390-5.
25. Patel P, Dhillon A, Popovic ZB, Smedira NG, Rizzo J, Thamilarasan M, et al. Lef ventricular outflow tract obstruction in hypertrophic cardiomyopathy patient without severe septal hypertrophy: implications of mitral valve and papillary muscle abnormalities assessed using cardiac magnetic resonance and echocardiography. Circ Cardiovasc Imaging. 2015;8:e003132.

26. Chan RH, Maron BJ, Olivotto I, Pencina MJ, Assenza GE, Haas T, et al. Prognostic value of quantitative contrast-enhanced cardiovascular magnetic resonance for the evaluation of sudden death risk in patients with hypertrophic cardiomyopathy. Circulation. 2014;130:484-95.

27. Olivotto I, Ommen SR, Maron MS, Cecchi F, Maron BJ. Surgical myectomy versus alcohol septal ablation for obstructive hypertrophic cardiomyopathy. Will there ever be a randomized trial? J Am Coll Cardiol. 2007;50:831-4.

Key Words: hypertrophic cardiomyopathy, outcomes, surgical myectomy

Readers who found these articles interesting may also like to read the following papers found in recent and future issues of our sister publications, Seminars in Thoracic and Cardiovascular Surgery and Operative Techniques in Thoracic and Cardiovascular Surgery!

\section{Congenital Heart Disease}

Current Readings: Pulmonary Valve Replacement for Pulmonary Valve Insufficiency in Formerly Repaired Tetralogy of Fallot. Brian Kogon. Semin Thorac Cardiovasc Surg 2015; Spring; 27(1):57-64.

Original Submission: Technical Performance Score as a predictor for post discharge reintervention in valve sparing Tetralogy of Fallot repair. Meena Nathan. Semin Thorac Cardiovasc Surg 2014; Winter; 26(4): 297-303.

Editorial Commentary: Technical performance anxiety: utility of the Technical Performance Scale in predicting later intervention after repair of Tetralogy of Fallot. Jonathan Chen. Semin Thorac Cardiovasc Surg 2014; Winter; 26(4):304-305.

State of the Art: Interrupted Aortic Arch. Richard Jonas. Expected Publication October 2015.

Original Submission: Should Tricuspid annuloplasty be performed with pulmonary valve replacement for pulmonary regurgitation in repaired tetralogy of fallot? Pranava Sinha. Expected Publication October 2015.

Original Submission: Unsatisfactory early and late outcomes after Fontan surgery delayed to adolescence and adulthood. Yves D'Udekem. Expected Publication October 2015.

Discussions in Cardiothoracic Treatment and Care: Tetralogy of Fallot. Charles Fraser. Expected Publication October 2015.

Pulmonary root translocation for anatomical repair of congenitally corrected transposition of the Great Arteries. Jose Pedro da Silva. Oper Tech Cardiovasc Surg 2014; Autumn; 19(3):304-323.

Melody Valve for Mitral Valve Replacement. Sitaram M. Emani. Oper Tech Thorac Cardiovasc Surg 2014; Winter; 19(4):454-463.

Single-Stage Neonatal Repair of Taussig-Bing Anamaly. Bahaaldin Alsoufi. Oper Tech Thorac Cardiovasc 2014; Winter; 19(4): 464-481. 


\begin{abstract}
APPENDIX
When isolated alcohol septal ablation was removed from the analysis (total $\mathrm{n}=1464$, number of composite events $=144$ ), the results of the forward stepwise multivariable Cox proportional hazard survival analysis were similar and as follows: Age (hazard ratio [HR], 1.17 [1.02-1.38]), coronary artery disease (CAD) (HR, 1.62 [1.11-2.43]), worsening New York Heart Association (NYHA) class (HR, 1.39 [1.10-1.91]), and atrial fibrillation (AF) (HR, 1.79 [1.22-2.58]) predicted higher events, whereas surgery as a time-dependent covariate (HR, 0.63 [0.44-0.84]) was associated with improved event-free survival (all $P<.01$ ).

When only patients with maximal left ventricular outflow tract (LVOT) gradient $50 \mathrm{~mm} \mathrm{Hg}$ or greater were included in the analysis $(n=1425$, number of events $=147)$, the results
\end{abstract}

of forward stepwise multivariable Cox proportional hazard survival analysis were similar and as follows: Age (HR, 1.23 [1.03-1.48]), CAD (HR, 1.91 [1.28-2.86]), worsening NYHA class (HR, 1.54 [1.19-1.99]), and AF (HR, 1.95 [1.36-2.82]) predicted higher events, whereas surgery as a time-dependent covariate (HR, 0.49 [0.34-0.70]) was associated with improved event-free survival (all $P<.05$ ).

Likewise, when patients with known significant $C A D$ were excluded from the analysis $(\mathrm{n}=1295$, number of events $=116$ ), the results of the forward stepwise multivariable Cox proportional hazard survival analysis were similar and as follows: Age (HR, 1.26 [1.05-1.51]), worsening NYHA class (HR, 1.68 [1.25-2.23]), and AF (HR, 1.61 [1.06-2.45]) predicted higher events, whereas surgery as a time-dependent covariate (HR, 0.46 [0.31-0.70]) was associated with improved event-free survival (all $P<.05$ ). 